\title{
Research on Collaborative Innovation Model of manufacturing SMEs
}

\author{
Xiaoxiao $\mathrm{Li}^{\mathrm{a}}$, Fuchun Sun ${ }^{\mathrm{b}}$ \\ School of Mechanical, Chengdu University, Sichuan 610106, China. \\ a960645733@qq.com, b55007410@qq.com
}

Keywords: Manufacturing industry; SMEs; collaborative innovation; model.

\begin{abstract}
Scientific innovation is the party and the country to support the strategic development priorities, Traditional manufacturing SMEs is a large group which is the most inactive in independent innovation, Analyzed the main restricted cause of manufacturing SMEs innovation. Collaborative innovation is an important development direction of enterprise innovation, in view of each main agent of collaborative innovation, Considering the government has an important guiding role in the development of the enterprise, In line with the principles of government to promote collaborative innovation, Proposed to collaborative innovation model to improve the innovation ability of manufacturing SMEs, for the rapid development of enterprise has important theoretical significance.
\end{abstract}

\section{Introduction}

To enter the second decade of the 21st century, transformation and upgrading of the Chinese industrial economy into the fast lane, from "made in China" to "created in China" strategic across also gradually become more and more industrial enterprise Shared vision. To do this, change the living conditions of traditional extensive manufacturing, resource consumption and low levels of competition in the disorderly market become imperative to enhance the capability of independent innovation, take the "innovation-driven, innovation -development," the road is the most wise choice[1].SMEs are an important subject of innovation, Traditional manufacturing SMEs to carry out independent innovation enthusiasm generally is low, the single factor innovation has become more and more difficult[2]. Government' s guidance can to strengthen contact of SMEs and institutes, to find a suitable object of collaborative innovation for the enterprise, can also provide effective support for Innovation Stakeholder cross, asymmetric information and limited resources In the collaborative innovation process.

\section{Main Factors Restricting Innovation in Manufacturing SMEs}

Significantly lower penetration of innovative activities for SMEs, the manufacturing enterprises mainly through the introduction of technology innovation at this stage, on the whole has not yet entered the stage of development of independent innovation. Situation of Chinese traditional manufacturing innovation as follows:

First, the overall awareness of independent innovation of enterprises still lack ,the degree of innovation involved in the practice is not high;

Second, enterprise innovation funding channels more single, input level is significantly lower, Policy capital investment insufficient, failed to attract more social capital to participate in innovation activities;

Third, independent innovation ability is generally low, the lack of high-level innovative talents which enhance the capability of independent innovation has become a bottleneck;

Fourth, the overall level of independent innovation of traditional manufacturing is not high, the amplitude level of innovation and improve the comprehensive competitiveness of the presence status is generally lower than expected;

Fifth, the traditional manufacturing enterprise still needs to be improved awareness of intellectual property, patent applications, trademarks and other intellectual property registration work carried out was not ideal, directly affect the effect of innovation activities; 
Sixth, to encourage traditional manufacturing industry' s innovation and matching the types of policy and service system is not perfect, affecting enterprise innovation initiative.

\section{The Model of Manufacturing SMEs Collaborative Innovation}

From a macro terms, to promote collaborative innovation needs government support and guidance in the capital, talent, technology, policy, for further collaboration innovation activities of SMEs. For manufacturing SMEs in different stages of growth, different synergistic innovative features and problems encountered, we should distinguish the different features of manufacturing SMEs, then provide good collaborative innovation system. In order to effectively integrate resources and allocation of resources to support collaborative innovation in manufacturing SMEs. At the same time, the government needs to increase investment in basic research, strengthen the guidance and support, to create a good environment for collaborative innovation.

\subsection{Collaborative Innovation Body.}

Manufacturing SMEs collaborative innovation system includes enterprises, government, research institutes and intermediaries4. Enterprise is the agent of the collaborative innovation, research institutions is the source of technology transfer, government is the guide of technical innovation, intermediary institutions is the supporting power of collaborative innovation5. Collaborative innovation is different from independent innovation, its main body in multiple layers and multiple links, the flow of agent between the production factors, knowledge, information and other resources are also constantly changing. At the same time, cooperative innovation include internal collaboration and external collaboration, internal collaborative innovation agent mainly refers to the enterprise itself, the realization of outside collaborative innovation is required to interact with enterprises between other related agents. From the perspective of the agents, collaborative innovation includes not only between enterprises and research institutes, but also including the innovation of the enterprises and enterprises, the innovation of enterprises and intermediary institutions.

Manufacturing SMEs are agent of collaborative innovation, which according to the dynamic needs of the market to determine the direction of innovation to ensure innovation and market demand docking. In the process of cooperative innovation, the enterprise due to its own characteristics, need other agent together, can effective implementation of technology innovation activities. Enterprise is the main force of promoting cooperative innovation, production, and the enterprise clustering collaborative innovation, has become a major trend in today's economic development of science and technology.

Research institutions is the cradle of new technology. Research institutes engaged in basic research, no commercial objectives, collaborative innovation can strengthen research institutions research efforts on the needs of enterprise technology innovation. In addition, Manufacturing SMEs in cooperation with research institutes from the introduction of technology to collaborative innovation of talent and management advantages, which can form a solid partnership of shared interests after the in-depth development.

Government as facilitator of manufacturing SMEs, is an important part of collaborative innovation. The government in the process of collaborative innovation play a macro-control, financial support and coordination to promote service function6. Through the government guidance and the institutional arrangements, can promote enterprise, university and scientific research institutions to play their respective advantages, effective integration of resources, complementary advantages, strengthen the technical promotion application and industrialization, promote the transformation of scientific and technological achievements.

Specialized agencies to provide social services of collaborative innovation for all kinds of social subjects such as enterprises, universities, and research institutions, to support innovation and promote scientific and technological achievements.

\subsection{Government to Promote Collaborative Innovation Principle.}

Government support for manufacturing SME cooperative innovation refers to the government formulate related policies and measures, provide a useful environment for the development of 
manufacturing SME, thereby promoting enterprise collaborative innovation. The government to promote collaborative innovation principles mainly include:

Adhere to the basic role of market principles. For manufacturing SMEs, the main technical innovation based on market demand guidelines, collaborative innovation activities should also adhere to the basic role of the market type .Government in supporting the manufacturing SMEs in the process of the development, according to market rules are needed to support and guide the collaborative innovation activities.

Adhere to the principle of division of labor. In the process of collaborative innovation, collaborative innovation agent should clarify the main strengths and weaknesses, their duties and play to their strengths, to establish a comprehensive system of collaborative innovation and collaborative innovation networks, to jointly promote the collaborative innovation activities in manufacturing SMEs.

Adhere to the principle of the stage. Different needs at different stages of collaborative innovation in manufacturing SMEs, the corresponding need for targeted measures are also different. In view of the different stages of enterprise development, using the different policy combination, realize the scrolling support, forming long-term service support system for the business enterprise growth process.

Adhere to the principle of innovation. Innovation is the purpose of collaborative innovation, enterprise should be the agent of innovative development, to strengthen research cooperation and to promote the development of enterprise innovative strategy, design SME growth path, increase innovation investment, through collaborative innovation breakthrough technical barriers to enterprise and industry, obtain independent intellectual property rights, trademarks, brand and technical standards.

\subsection{Collaborative Innovation Model.}

In collaborative innovation system, according to the characteristics of the growth of manufacturing SMEs, Cooperative mode of technological Innovation including cooperation between enterprises, research cooperation, industrial clusters.

The cooperative mode among enterprises. Technical cooperation between enterprises is an important way in collaborative innovation, Manufacturing SMEs through the creation of innovative alliances with related businesses, around a technology or product to expand cooperation, enterprise size limitation [7]. Collaborative innovation among SMEs in the manufacturing sector can promote the expansion of community-scale enterprises, Improve the ability to resist risks communities. In this mode, both companies based on market information needs and technology development characteristics, to establish cooperative relations.

Cooperative is the most important mode of collaborative innovation. In general, manufacturing SMEs only rely on their own to achieve innovation is unrealistic. Universities and research institutions have the technology, talent, information, testing, and other advantages, the company's market development capability is strong, which can effectively achieve innovation through the complementary advantages. Scientific research institutions for technical innovation research, Enterprises to take advantage of market technology to the market and the market demand information feedback to the scientific research institutes, Realize the benign cycle of collaborative innovation. Way of "industry-university-institute" cooperation, including joint training, SMEs set up a laboratory in colleges and universities, Or talented person and teams of university to build enterprise technology centers and research project cooperation, etc., are the important way of "industry-university-institute" cooperation.

Industrial clusters. Industrial cluster is the main form of collaborative innovation of SMEs. Cluster approach is to enhance the overall innovation capability through cluster learning, "pull effect" and "crowding out effect [1]. The way to realize the cluster learning includes sending the technical personnel, establishing the Joint Institute and association, etc., and cooperate with the relevant laws and regulations to regulate the behavior of the members of the cluster. Cluster innovation is to promote the independent innovation of enterprises in the cluster through competition and cooperation, including the cooperation between enterprises in different stages of production and the competition 
between competitors, these cooperation and competition to promote the innovation and development of enterprises. Industrial agglomeration can effectively make use of the economic relations and technological relations between industries to realize collaborative innovation. Cluster in collaborative innovation process, to avoid disorderly competition, needs the government to formulate relevant policy and system specification, and through cultural environment construction, guide the collaborative innovation behavior.

\section{Summary}

Manufacturing SMEs own characteristics and the important role of collaborative innovation collaborative innovation determines the important role of SMEs in the manufacturing sector, the government can achieve a lot of synergy innovative integration of resources in each of the main collaborative research and innovation, access to effective allocation of resources, save costs and reduce the risk of innovation. When analyzing collaborative innovation model, not only from a research cooperation, research and technical cooperation and other aspects of industrial clusters between enterprises are research priorities and direction of the government in different stages of collaborative innovation initiatives to promote the development of enterprises, but also focus on the role of intermediaries to create a more comprehensive development environment.

\section{Acknowledgements}

Thanks to the fund support of Chengdu Science and Technology Bureau: University and local collaborative innovation, together with the establishment of manufacturing and research service platform for SMEs (project number: 2014-RK00-00061-ZF).

\section{References}

[1]. Zhenyu Zhang. Research on factors of independent innovation dynamic and its impact path in China traditional manufacyuring SMES [D].Southwest Jiaotong University, 2013.

[2]. Xiaojie Li. Study of the mechanism to promote SMEs collaborative innovation of Technology [D].South China University of Technology, 2014.

[3]. Huatao Peng, Long Ma, Ying Wu. Promoting collaborative innovation should strengthen the government's leading role [J]. Economic Review, 2013, 08:13-17.

[4]. Xiaoling Wang. A preliminary study on the innovation network of Henan animation industry [J]. Journal of Hubei University of Science, 2013, 07:127-128.

[5]. Yan Lu, Xiaosheng Zhang. Research on technical innovation organization barrier of national defense science and technology industry [J]. Science \& Technology Progress and Policy, 2012, 02:63-65.

[6]. Jianguang GAO. Analysis on the key barriers to the technological progress of enterprises [J].Technology and Economy Information of Shipbuilding Industry, 2004, 05:41-44.

[7]. Tongshan Liu. Technology innovation mode and development countermeasure of Agricultural enterprise [J]. Modern Management Science, 2014, 03:48-50. 